\title{
Article \\ Cytokine/Chemokine Release Patterns and Transcriptomic Profiles of LPS/IFN $\gamma$-Activated Human Macrophages Differentiated with Heat-Killed Mycobacterium obuense, M-CSF, or GM-CSF
}

\author{
Samer Bazzi ${ }^{1, *}$, Emale El-Darzi ${ }^{2}$, Tina McDowell ${ }^{3}$, Helmout Modjtahedi ${ }^{4}$ (D), Satvinder Mudan ${ }^{5}$, Marcel Achkar ${ }^{6}$, \\ Charles Akle ${ }^{5}$, Humam Kadara ${ }^{3}$ and Georges M. Bahr ${ }^{2}$
}

1 Division of Biology and Environmental Science, Faculty of Arts and Sciences, University of Balamand, 33 Amioun, Al Kurah 100, Lebanon

2 Department of Biomedical Sciences, Faculty of Medicine and Medical Sciences, University of Balamand, 33 Amioun, Al Kurah 100, Lebanon; emaledarzi@gmail.com (E.E.-D.); georges.bahr@balamand.edu.lb (G.M.B.)

3 Department of Translational Molecular Pathology, The University of Texas MD Anderson Cancer Center, Houston, TX 77030, USA; CLMcDowell@mdanderson.org (T.M.); HKadara@mdanderson.org (H.K.)

4 School of Life Sciences, Pharmacy and Chemistry, Faculty of Science, Engineering and Computing, Kingston University, Kingston upon Thames, Surrey KT1 2EE, UK; H.Modjtahedi@kingston.ac.uk

check for updates

Citation: Bazzi, S.; El-Darzi, E.; McDowell, T.; Modjtahedi, H.; Mudan, S.; Achkar, M.; Akle, C.; Kadara, H.; Bahr, G.M.

Cytokine/Chemokine Release Patterns and Transcriptomic Profiles of LPS/IFN $\gamma$-Activated Human Macrophages Differentiated with Heat-Killed Mycobacterium obuense, M-CSF, or GM-CSF. Int. J. Mol. Sci. 2021, 22, 7214. https://doi.org/ 10.3390/ijms22137214

Academic Editor: Nadia Lampiasi

Received: 3 June 2021

Accepted: 30 June 2021

Published: 5 July 2021

Publisher's Note: MDPI stays neutral with regard to jurisdictional claims in published maps and institutional affiliations.

Copyright: () 2021 by the authors. Licensee MDPI, Basel, Switzerland. This article is an open access article distributed under the terms and conditions of the Creative Commons Attribution (CC BY) license (https:// creativecommons.org/licenses/by/ $4.0 /)$.
5 The London Clinic, 20 Devonshire Pl, London W1G 6BW, UK; mudans@aol.com (S.M.); cakle@me.com (C.A.)

6 Clinical Laboratory, Nini Hospital, Tripoli 1434, Lebanon; marcel.achkar@hopitalnini.com

* Correspondence: samer.bazzi@balamand.edu.lb; Tel.: +961-6-930250 (ext. 3832)

\begin{abstract}
Macrophages (M $\varphi s)$ are instrumental regulators of the immune response whereby they acquire diverse functional phenotypes following their exposure to microenvironmental cues that govern their differentiation from monocytes and their activation. The complexity and diversity of the mycobacterial cell wall have empowered mycobacteria with potent immunomodulatory capacities. A heat-killed (HK) whole-cell preparation of Mycobacterium obuense (M. obuense) has shown promise as an adjunctive immunotherapeutic agent for the treatment of cancer. Moreover, HK M. obuense has been shown to trigger the differentiation of human monocytes into a monocytederived macrophage (MDM) type named Mob-MDM. However, the transcriptomic profile and functional properties of Mob-MDMs remain undefined during an activation state. Here, we characterized cytokine/chemokine release patterns and transcriptomic profiles of lipopolysaccharide (LPS)/interferon $\gamma$ (IFN $\gamma$ )-activated human MDMs that were differentiated with HK M. obuense (Mob-MDM(LPS/IFN $\gamma)$ ), macrophage colony-stimulating factor M-MDM(LPS/IFN $\gamma)$ ), or granulocyte/macrophage colony-stimulating factor (GM-MDM(LPS/IFN $\gamma)$ ). Mob-MDM(LPS/IFN $\gamma$ ) demonstrated a unique cytokine/chemokine release pattern (interleukin (IL)-10 low , IL-12/23p40 low , IL-23p19/p40 low , chemokine (C-x-C) motif ligand (CXCL) $9^{\text {low }}$ ) that was distinct from those of M$\operatorname{MDM}(\mathrm{LPS} / \mathrm{IFN} \gamma)$ and GM-MDM(LPS/IFN $\gamma)$. Furthermore, M-MDM(LPS/IFN $\gamma)$ maintained IL-10 production at significantly higher levels compared to GM-MDM(LPS/IFN $\gamma$ ) and Mob-MDM(LPS/ IFN $\gamma$ ) despite being activated with $\mathrm{M} 1-\mathrm{M} \varphi$-activating stimuli. Comparative RNA sequencing analysis pointed to a distinct transcriptome profile for Mob-MDM(LPS/IFN $\gamma$ ) relative to both M$\mathrm{MDM}(\mathrm{LPS} / \mathrm{IFN} \gamma)$ and GM-MDM(LPS/IFN $\gamma)$ that comprised 417 transcripts. Functional gene-set enrichment analysis revealed significant overrepresentation of signaling pathways and biological processes that were uniquely related to Mob-MDM(LPS/IFN $\gamma)$. Our findings lay a foundation for the potential integration of HK M. obuense in specific cell-based immunotherapeutic modalities such as adoptive transfer of $\mathrm{M} \varphi \mathrm{s}(\mathrm{Mob}-\mathrm{MDM}(\mathrm{LPS} / \mathrm{IFN} \gamma))$ for cancer treatment.
\end{abstract}

Keywords: Mycobacterium obuense; immunomodulation; monocyte-derived macrophages; macrophage activation; RNA sequencing 


\section{Introduction}

Macrophages $(\mathrm{M} \varphi \mathrm{s})$ are known for their exceptional degree of plasticity whereby they display diversified phenotypes and functions following exposure to various cues from the surrounding milieu [1]. Human $\mathrm{M} \varphi$ s are generally classified into "proinflammatory/classically activated" M1 and "anti-inflammatory/alternatively activated" M2 phenotypes. M1-M $\varphi$ s produce significant amounts of proinflammatory cytokines (e.g., interleukin (IL)-1 $\beta$, IL-6, IL-12, IL-23, and tumor necrosis factor alpha (TNF- $\alpha$ )) and retain robust and antitumor capabilities in certain stages of cancer development and progression. In contrast, $\mathrm{M} 2-\mathrm{M} \varphi$ s release substantial amounts of anti-inflammatory cytokines (e.g., IL-10 and transforming growth factor (TGF- $\beta$ )) and contribute to tissue regeneration, angiogenesis, and tumor progression [2,3]. To obtain activated human $\mathrm{M} \varphi$ phenotypes in vitro, isolated monocytes are initially primed with maturation/differentiation factors such as granulocyte/macrophage colony-stimulating factor (GM-CSF) and macrophage colony-stimulating factor (M-CSF) to generate nonactivated M1-like and M2-like monocytederived macrophages (MDMs), respectively [4-6]. Following the maturation or differentiation stage, M1-like $\mathrm{M} \varphi$ s are stimulated with lipopolysaccharide (LPS) and interferon $\gamma$ (IFN $\gamma$ ) to induce the activated M1-M $\varphi$ phenotype, while M2-like $\mathrm{M} \varphi$ s are stimulated with interleukin (IL)-4 \pm IL-13, IL-10, TGF- $\beta$, immune complexes, or glucocorticoids to induce various activated $\mathrm{M} 2-\mathrm{M} \varphi$ phenotypes $[7,8]$.

The complexity and diversity of the mycobacterial cell wall have empowered mycobacteria with a potent immunomodulatory capacity [9]. Such mycobacteria-associated immunomodulatory activities have been mainly attributed to various mycobacterial cell wall components, serving as pathogen-associated molecular patterns (PAMPs) that are recognized by specific pathogen recognition receptors (PRRs) expressed on various innate immune cells, including monocytes, and macrophages $[10,11]$. Over the past 10 years, there has been an increasing interest in exploring the immunotherapeutic potential [12-14] and the in vitro immunomodulatory properties of a heat-killed (HK) whole-cell preparation of Mycobacterium obuense (M. obuense), also known as IMM-101 [15-18]. In a phase I clinical trial, HK M. obuense was shown to be safe and well tolerated when used alone in patients with stage III/IV metastatic melanoma [12]. A phase II clinical trial reported that a combination treatment of HK M. obuense and conventional gemcitabine chemotherapy was safe and resulted in a significant increase in the overall survival of patients with metastatic pancreatic cancer [13]. HK M. obuense is currently being investigated as an immunotherapeutic agent in combination with anti-PD-1 in a phase II trial (NCT03711188) involving patients with advanced melanoma. In addition, an ongoing phase III clinical trial (NCT04442048) is examining whether immunization with HK M. obuense can diminish the frequency of severe respiratory and severe acute respiratory syndrome coronavirus 2 (SARS-CoV-2)related infections among cancer patients. Our group previously demonstrated the ability of HK M. obuense to modulate the surface expression of different categories of cells surface receptors on whole-blood human monocytes [16], as well as to trigger the differentiation of human monocytes into a nonactivated $\mathrm{M} \varphi$ type (Mob-MDM) that is quite distinct from the nonactivated M $\varphi$ phenotypes generated by M-CSF (M-MDM) or GM-CSF (GM-MDM) [18]. Nonactivated Mob-MDMs exhibited significantly increased and spontaneous release of the proinflammatory cytokines IL- 6 and TNF- $\alpha$ and chemokine (C-x-C) motif ligand (CXCL) 8, relative to nonactivated M-MDMs and GM-MDMs. Moreover, all three nonactivated $\mathrm{M} \varphi$ types did not release spontaneous detectable levels of IL-10, IL-12p40, IL-12p70, and IL-23p19/p40. In the same study, genome-wide gene expression profiling combined with functional enrichment analysis revealed unique gene sets and networks suggestive of a proinflammatory M1-like M $\varphi$ phenotype in Mob-MDMs compared with both M-MDMs and GM-MDMs [18].

Because human nonactivated MDMs display a distinct pattern of phenotypic and functional characteristics compared to activated MDMs [19,20], this study sought to characterize M-MDMs, GM-MDMs, and Mob-MDMs during an activated state. Therefore, the three above-mentioned nonactivated MDM types were activated with LPS and 
IFN $\gamma$ to generate the following MDM types: M-MDM(LPS/IFN $\gamma)$, GM-MDM(LPS/IFN $\gamma$ ), and Mob-MDM(LPS/IFN $\gamma)$, whereby the $\mathrm{M} \varphi$ nomenclature proposed by Murray et al. was adopted [1]. The aims of this study were, first, to characterize the cytokine and chemokine secretion patterns of M-MDM(LPS/IFN $\gamma)$, GM-MDM(LPS/IFN $\gamma)$, and Mob$\operatorname{MDM}(\mathrm{LPS} / \mathrm{IFN} \gamma)$ and, second, to perform genome-wide transcriptome profiling of the three LPS/IFN $\gamma$-activated MDM types.

\section{Results}

2.1. Patterns of Cytokine and Chemokine Secretion by M-MDM(LPS/IFN $\gamma)$, $G M-M D M(L P S / I F N \gamma)$, and Mob-MDM(LPS/IFN $\gamma)$

To examine the functional characteristics of different LPS/IFN $\gamma$-activated MDMs, culture supernatants of M-MDM(LPS/IFN $\gamma)$, GM-MDM(LPS/IFN $\gamma$ ), and Mob-MDM(LPS/ IFN $\gamma$ ) were screened for various secreted cytokines and chemokines. GM-MDM(LPS/IFN $\gamma$ ) displayed significantly $(p<0.05)$ higher secretion levels of the M1-M $\varphi$ signature cytokine, IL-12/23p40, as compared to M-MDM(LPS/IFN $\gamma$ ) and Mob-MDM(LPS/IFN $\gamma)(\sim 7.5$-fold and $~ 10$-fold, respectively; Figure 1). Of note, GM-MDM(LPS/IFN $\gamma$ ) were found to release substantial amounts of another M1-M $\varphi$ marker, IL-23p19/p40, while M-MDM(LPS/IFN $\gamma)$ and Mob-MDM(LPS/IFN $\gamma$ ) were characterized by their undetectable and low-level release of IL-23p19/p40, respectively (Figure 1). Additionally, GM-MDM(LPS/IFN $\gamma$ ) showed a trend toward higher IL-12p70 production relative to M-MDM(LPS/IFN $\gamma$ ) and Mob$\operatorname{MDM}(\mathrm{LPS} / \mathrm{IFN} \gamma)$; however, this difference did not achieve statistical significance (Figure 1). Supernatants from M-MDM(LPS/IFN $\gamma)$ cultures demonstrated significantly $(p<0.05)$ increased levels of chemokine (C-C motif) ligand 5 (CCL5) and the M2-M $\varphi$ signature cytokine marker, IL-10, as well as decreased levels of M1-M $\varphi$ marker, IL-6, when compared with supernatants from GM-MDM(LPS/IFN $\gamma$ ) and Mob-MDM(LPS/IFN $\gamma$ ) cultures (Figure 1). In addition, Mob-MDM(LPS/IFN $\gamma)$ exhibited significantly $(p<0.05)$ reduced CXCL9 secretion as compared to M-MDM(LPS/IFN $\gamma$ ) and GM-MDM(LPS/IFN $\gamma$ ) (Figure 1). Mob-MDM(LPS/IFN $\gamma$ ) released lower amounts of CCL2 and CCL22 as compared to GM-MDM(LPS/IFN $\gamma)$. No significant differences were detected between MMDM(LPS/IFN $\gamma$ ), GM-MDM(LPS/IFN $\gamma)$, and Mob-MDM(LPS/IFN $\gamma$ ) in terms of TGF- $\beta 1$, TNF- $\alpha$, and M-CSF production (Figure 1). All in all, the above-reported data strongly indicate that Mob-MDM(LPS/IFN $\gamma$ ) are characterized by a distinct cytokine and chemokine secretion pattern (IL-10 $0^{\text {low }}$, IL-12/23p $40^{\text {low }}$, IL-23p $19 / \mathrm{p} 40^{\text {low }}$, and CXCL9 ${ }^{\text {low }}$ ) from that of M-MDM(LPS/IFN $\gamma$ ) and GM-MDM(LPS/IFN $\gamma)$. Moreover, the cytokine release patterns of GM-DM(LPS/IFN $\gamma)$ and M-MDM(LPS/IFN $\gamma)$ strongly correlate with those of M1-M $\varphi s$ and $\mathrm{M} 2-\mathrm{M} \varphi \mathrm{s}$, respectively. The cytokine and chemokine secretion profiles of nonactivated M-MDMs, GM-MDMs, and Mob-MDMs have been characterized in a previous study [18]. 


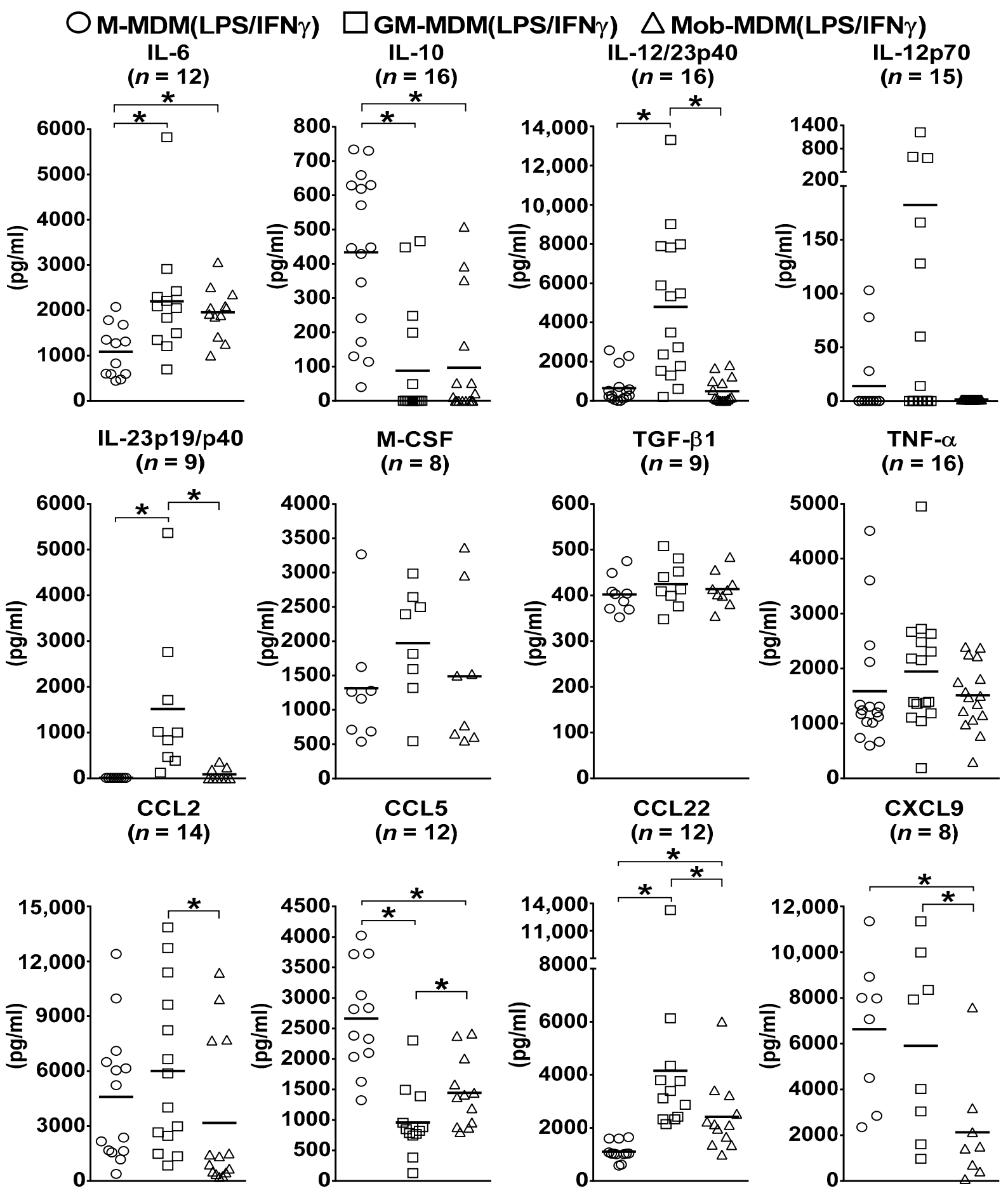

Figure 1. Cytokine and chemokine secretion by lipopolysaccharide (LPS)/interferon $\gamma$ (IFN $\gamma$ )-activated monocyte-derived macrophages (MDMs). Macrophage colony-stimulating factor MDMs (M-MDMs), granulocyte/macrophage colonystimulating factor MDMs (GM-MDM), and heat-killed Mycobacterium obuense MDMs (Mob-MDMs) were generated and activated with LPS and IFN $\gamma$ for $24 \mathrm{~h}$ as described below (see the Materials and Methods section (Section 4)). Cytokine and chemokine levels were determined in M-MDM(LPS/IFN $\gamma)$, GM-MDM(LPS/IFN $\gamma)$, and Mob-MDM(LPS/IFN $\gamma)$ culture supernatants by ELISA. Scatter plots demonstrate chemokine or cytokine concentration $(\mathrm{pg} / \mathrm{mL})$ in different LPS/IFN $\gamma$ activated MDM culture supernatants. Horizontal bars indicate group mean values of cytokine or chemokine concentration of at least 8 independent donors. One-way ANOVA, followed by Tukey's post-hoc test, was performed to determine statistically significant differences in cytokine/chemokine secreted levels ( $\left.{ }^{*} p<0.05\right)$. Circles represent M-MDM(LPS/IFN $\left.\gamma\right)$, squares represent GM-MDM(LPS/IFN $\gamma)$ and triangles represent Mob-MDM(LPS/IFN $\gamma)$. 


\subsection{Comparative Whole-Transcriptome Analysis of M-MDM(LPS/IFN $\gamma)$, GM-MDM(LPS/IFN $\gamma)$,} and $M o b-M D M(L P S / I F N \gamma)$

RNA sequencing (RNA-Seq) was carried out to profile the transcriptomes of LPS/IFN $\gamma$ activated Mob-MDMs, M-MDMs, and GM-MDMs, each derived from four independent donors. Sample preparation, sequencing, and analytical methods for RNA-Seq analysis of the three LPS/IFN $\gamma$-activated MDMs were performed as previously described [18]. Following filtering criteria ( $\geq 2$-fold change cut-off, $p<0.05$ ), a total of 1546 transcripts were differentially expressed among M-MDM(LPS/IFN $\gamma)$, GM-MDM(LPS/IFN $\gamma$ ), and Mob-MDM(LPS/IFN $\gamma$ ) (Supplementary Materials Table S1). Of the 1546 differentially expressed transcripts, 260 were identified as being upregulated in M-MDM(LPS/IFN $\gamma$ ) versus GM-MDM(LPS/IFN $\gamma$ ), while 262 were upregulated in GM-MDM(LPS/IFN $\gamma$ ) versus M-MDM(LPS/IFN $\gamma)$. Several M1-M $\varphi$-related genes belonging to different categories (e.g., IL6, IL12B (encoding for IL-12/23p40), IL23A (encoding for IL-23p19), and IL8 (encoding for CXCL8)) were expressed at significantly higher levels in GM-MDM(LPS/IFN $\gamma$ ) as compared to M-MDM(LPS/IFN $\gamma$ ) (Table 1). On the other hand, the expression levels of a set of M2-M $\varphi$-associated genes (e.g., ADAMDEC1, CCL17, CD36, CD163, IL10, $M A O A, S E P P 1, S O C S 2$, and STAB1) were significantly higher in M-MDM(LPS/IFN $\gamma$ ) relative to GM-MDM(LPS/IFN $\gamma$ ) (Table 1). Accordingly, our results clearly indicate that GM-MDM(LPS/IFN $\gamma$ ) and M-MDM(LPS/IFN $\gamma$ ) display M1-like and M2-like M $\varphi$ properties, respectively.

Table 1. Select transcripts significantly differentially expressed between lipopolysaccharide (LPS)/interferon $\gamma$ (IFN $\gamma$ )activated human monocyte-derived macrophages (MDMs) that were differentiated with macrophage colony-stimulating factor (M-MDM(LPS/IFN $\gamma)$ ) and granulocyte/macrophage colony-stimulating factor (GM-MDM(LPS/IFN $\gamma)$ ).

\begin{tabular}{|c|c|c|c|}
\hline RefSeq Transcript ID & Gene Symbol & Entrez Gene Name & FC (vs. GM-MDM(LPS/IFN $\gamma)$ ) \\
\hline NM_002933 & RNASE1 & Ribonuclease, RNase A family, 1 & 20.65 \\
\hline NM_006274 & CCL19 & Chemokine (C-C motif) ligand 19 & 18.02 \\
\hline NM_001400 & S1PR1 & sphingosine-1-phosphate receptor 1 & 11.92 \\
\hline NM_000240 & $M A O A$ & monoamine oxidase $\mathrm{A}$ & 10.01 \\
\hline NM_000572 & IL10 & Interleukin 10 & 7.88 \\
\hline NM_203416 & CD163 & CD163 molecule & 7.44 \\
\hline NM_004244 & CD163 & CD163 molecule & 7.38 \\
\hline NM_015136 & STAB1 & Stabilin 1 & 6.72 \\
\hline NM_001270471 & SOCS2 & Suppressor of cytokine signaling 2 & 5.16 \\
\hline NM_001270467 & SOCS2 & Suppressor of cytokine signaling 2 & 3.97 \\
\hline NM_014479 & ADAMDEC1 & ADAM-like, decysin 1 & 3.64 \\
\hline NM_001127443 & CD36 & CD36 molecule & 3.55 \\
\hline NM_002987 & CCL17 & Chemokine (C-C motif) ligand 17 & 3.45 \\
\hline NM_003877 & SOCS2 & Suppressor of cytokine signaling 2 & 3.22 \\
\hline NM_004994 & MMP9 & Matrix metallopeptidase 9 & 2.82 \\
\hline NM_001127444 & CD36 & CD36 molecule & 2.82 \\
\hline NM_001001547 & CD36 & CD36 molecule & 2.63 \\
\hline NM_001001548 & CD36 & CD36 molecule & 2.62 \\
\hline
\end{tabular}


Table 1. Cont.

\begin{tabular}{|c|c|c|c|}
\hline RefSeq Transcript ID & Gene Symbol & Entrez Gene Name & FC (vs. GM-MDM(LPS/IFN $\gamma)$ ) \\
\hline NM_181054 & HIF1A & $\begin{array}{l}\text { Hypoxia-inducible factor } 1 \text {, alpha } \\
\text { subunit (basic helix-loop-helix } \\
\text { transcription factor) }\end{array}$ & 2.48 \\
\hline NM_000072 & CD36 & CD36 molecule & 2.29 \\
\hline NM_005410 & SEPP1 & Selenoprotein $\mathrm{P}$, plasma, 1 & 2.13 \\
\hline NM_016584 & IL23A & Interleukin 23 subunit alpha (p19) & -2.34 \\
\hline NM_000584 & IL8 & Chemokine (C-X-C motif) ligand 8 & -2.46 \\
\hline NM_000759 & CSF3 & Colony-stimulating factor 3 & -2.49 \\
\hline NM_003775 & S1PR4 & Sphingosine-1-phosphate receptor 4 & -2.64 \\
\hline NM_001764 & $C D 1 B$ & CD1b molecule & -3.39 \\
\hline NM_000575 & IL1A & Interleukin 1 alpha & -3.63 \\
\hline NM_002438.1 & $M R C 1$ & Mannose receptor, C type 1 (CD206) & -3.96 \\
\hline NM_001025194 & CES1 & Carboxylesterase 1 & -3.97 \\
\hline NM_002990 & CCL22 & Chemokine (C-C motif) ligand 22 & -4.08 \\
\hline NM_001025195 & CES1 & Carboxylesterase 1 & -4.22 \\
\hline NM_001207019 & FCER2 & Fc fragment of IgE receptor II & -4.23 \\
\hline NM_002438 & MRC1 & Mannose receptor, C type 1 (CD206) & -4.37 \\
\hline NM_001266 & CES1 & carboxylesterase 1 & -4.38 \\
\hline NM_000600 & IL6 & Interleukin 6 & -4.63 \\
\hline NM_006770 & MARCO & $\begin{array}{l}\text { Macrophage receptor with } \\
\text { collagenous structure }\end{array}$ & -7.49 \\
\hline NM_002981 & CCL1 & Chemokine (C-C motif) ligand 1 & -8.71 \\
\hline NM_002187 & IL12B & Interleukin 12B (p40) & -15.28 \\
\hline
\end{tabular}

FC: fold change.

Hierarchical clustering analysis was performed to characterize gene clusters with differential patterns of expression among the three LPS/IFN $\gamma$-activated MDMs. A twodimensional hierarchical clustering of both transcripts and samples demonstrated that Mob-MDM(LPS/IFN $\gamma$ ) formed a separate cluster from both M-MDM(LPS/IFN $\gamma$ ) and GM-MDM(LPS/IFN $\gamma$ ) (Figure 2). We noted two gene clusters that displayed the lowest and highest expression in Mob-MDM(LPS/IFN $\gamma$ ) relative to both M-MDM(LPS/IFN $\gamma$ ) and GM-MDM(LPS/IFN $\gamma$ ) (Figure 2). These two clusters comprised 417 transcripts that were differentially expressed in Mob-MDM(LPS/IFN $\gamma$ ) versus both M-MDM(LPS/IFN $\gamma)$ and GM-MDM(LPS/IFN $\gamma$ ), but not between the latter two MDM types (Supplementary Materials Table S2). Gene ontology analysis revealed that Mob-MDM(LPS/IFN $\gamma$ ) profiles included cytokines/chemokines (e.g., CSF2, CXCL1, CXCL2, CXCL3, CXCL5, CXCL9, CXCL10, CXCL11, IL1B, and IL36G), G-protein-coupled receptors (e.g., CXCR4 and CXCR6), enzymes such as peptidases, phosphatases, and kinases (e.g., PRKCQ and CSNK1G3), transmembrane receptors (e.g., IL2RB and SEMA4D), transcription regulators (e.g., ANKRD22 and ASB2), and others such as SIGLEC10 (Supplementary Materials Table S2). 


\section{DM-MDM(LPS/FN $\gamma)$ ]GM-MDM(LPS/FN}

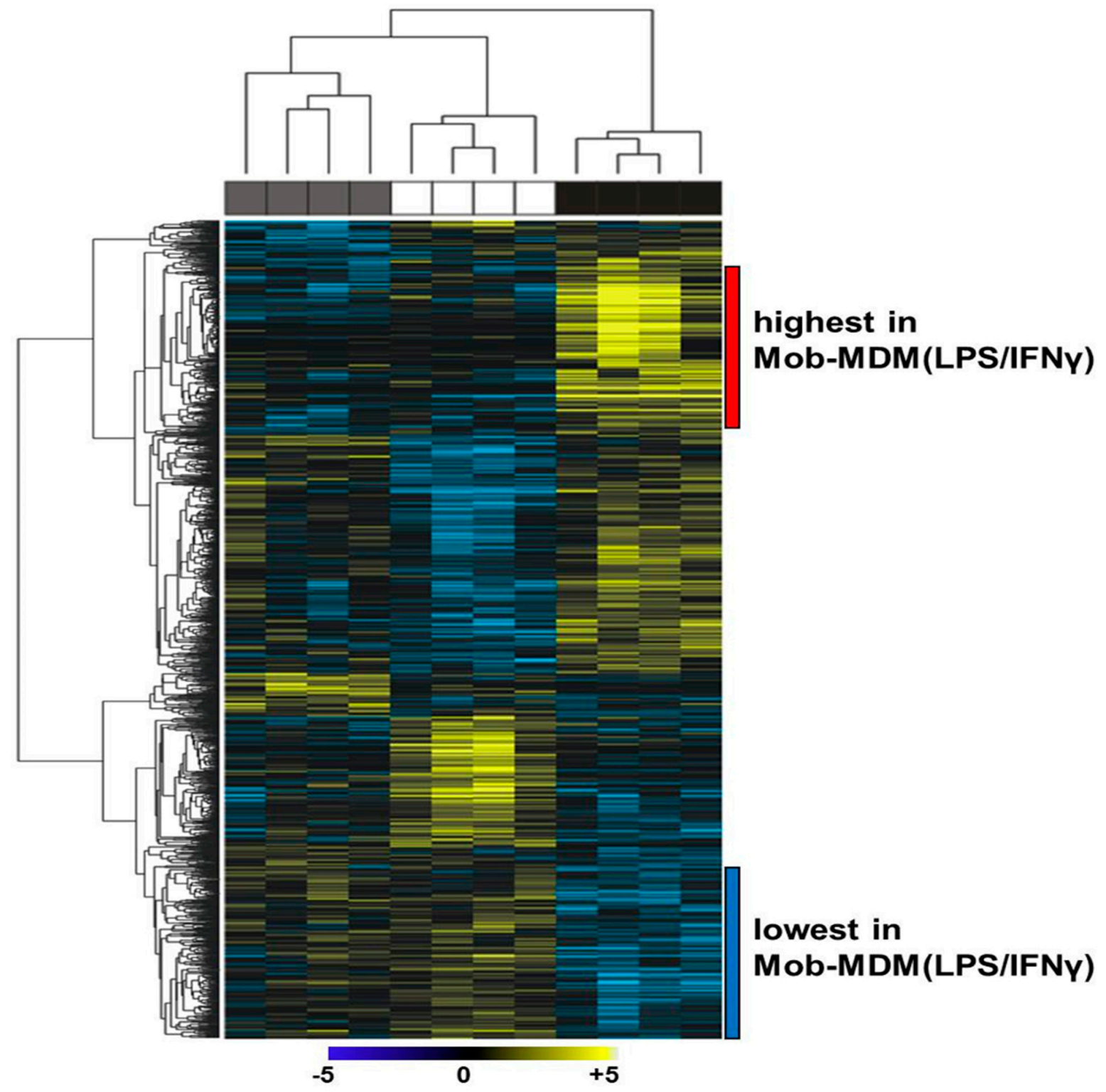

Figure 2. Whole-transcriptome analysis of lipopolysaccharide (LPS)/interferon $\gamma$ (IFN $\gamma$ )-activated monocyte-derived macrophages (MDMs). Macrophage colony-stimulating factor MDMs (M-MDMs), granulocyte/macrophage colonystimulating factor MDMs (GM-MDMs), and heat-killed Mycobacterium obuense MDMs (Mob-MDMs) were generated and activated with LPS and IFN $\gamma$ for $24 \mathrm{~h}$ as described below (see the Materials and Methods section (Section 4)) from four healthy donors $(n=12)$. Total RNA was isolated and then sequenced using the Ion Torrent platform (as described in the Materials and Methods section (Section 4)). Sequence alignment, followed by quantification of transcriptomes, was performed (as described in the Materials and Methods section (Section 4)). Transcripts $(n=1546)$ differentially expressed between M-MDM(LPS/IFN $\gamma)$, GM-MDM(LPS/IFN $\gamma$ ), and Mob-MDM(LPS/IFN $\gamma$ ) were identified based on a fixed-effects model with ANOVA and analyzed by hierarchical clustering. Columns represent samples and rows constitute the differentially expressed transcripts (yellow, relatively upregulated; blue, relatively downregulated).

Orthogonal validation of RNA-Seq data found similar differential patterns of expression of select cytokines/chemokines, namely IL8 (encodes for CXCL8), IL10 (encodes for IL-10), IL12B (encodes for IL-12/23p40), and TNF (encodes for TNF- $\alpha$ ), at both the transcript (Figure 3A) and protein (Figure 3B) levels in M-MDM(LPS/IFN $\gamma$ ), GM-MDM(LPS/IFN $\gamma$ ), and Mob-MDM(LPS/IFN $\gamma)$. 


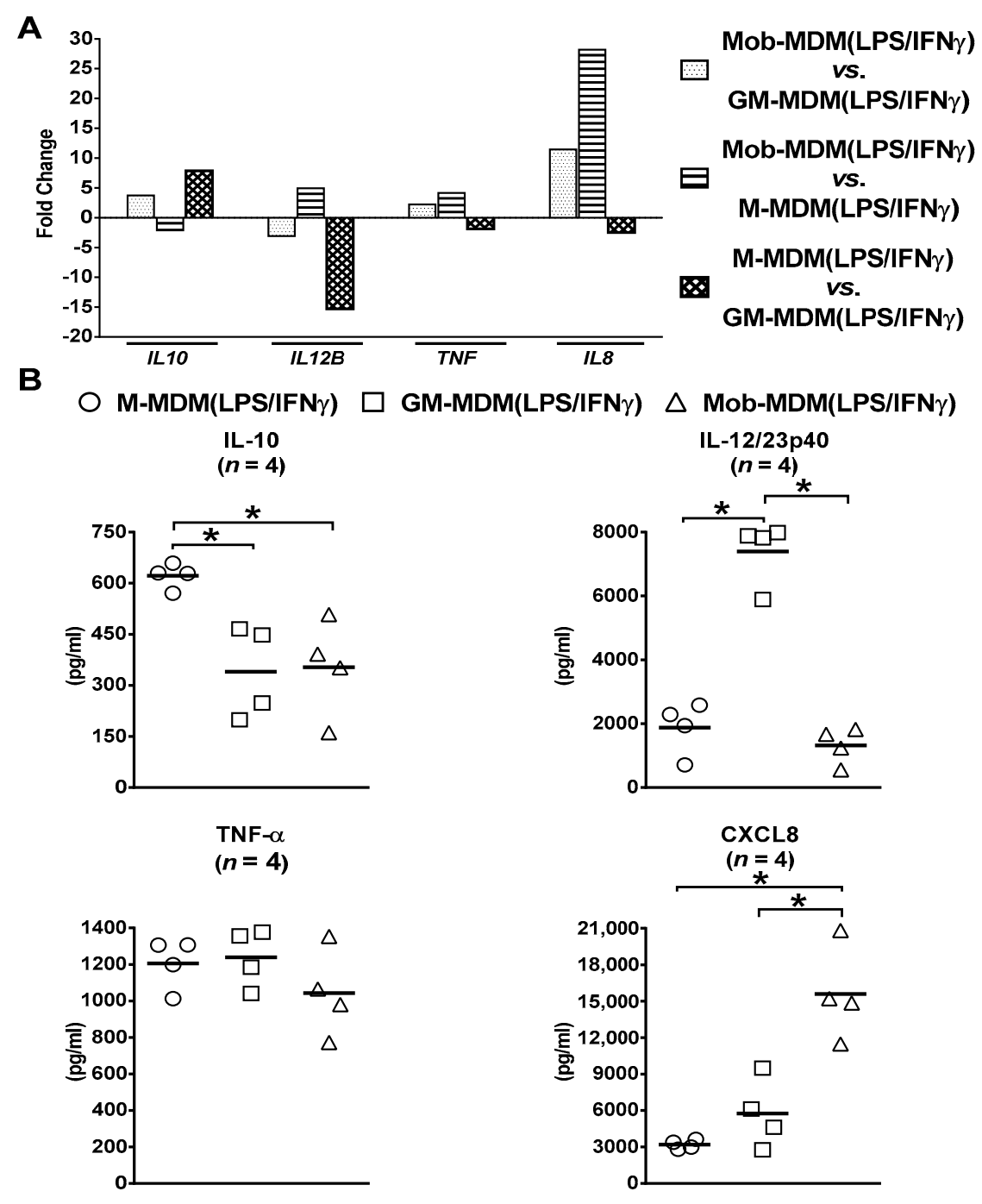

Figure 3. Confirmation of select cytokines and chemokines identified to be differentially expressed among lipopolysaccharide (LPS)/interferon $\gamma$ (IFN $\gamma)$-activated monocyte-derived macrophages (MDMs) by RNA sequencing (RNA-Seq). Macrophage colony-stimulating factor MDMs (M-MDMs), granulocyte/macrophage colony-stimulating factor MDMs (GM-MDMs), and heat-killed Mycobacterium obuense MDMs (MobMDMs) were generated and were activated with LPS/IFN $\gamma$ for $24 \mathrm{~h}$ (as described in the Materials and Methods section (Section 4)). The differential expression of (A) select cytokine/chemokine transcripts, namely interleukin 10 (IL10) (encodes IL-10), IL12B (encodes IL12/23p40), tumor necrosis factor (TNF) (encodes TNF- $\alpha$ ), and IL8 (encodes chemokine C-x-C motif ligand 8 (CXCL8)), in LPS/IFN $\gamma$-activated MDMs was confirmed at (B) the protein level by analysis of their secreted levels in M-MDM(LPS/IFN $\gamma)$, GM-MDM(LPS/IFN $\gamma$ ), and Mob-MDM(LPS/IFN $\gamma)$ culture supernatants by ELISA. (A) Column bars represent fold change for each cytokine or chemokine transcript, and (B) scatter plots demonstrate cytokine or chemokine concentration in culture supernatants of the three LPS/IFN $\gamma$-activated MDM types. The same MDMs were used for RNA-Seq and ELISA experiments. Horizontal bars indicate group mean values of cytokine or chemokine concentration of at least 4 independent donors. One-way ANOVA, followed by Tukey's post-hoc test, was performed to determine statistically significant differences in cytokine/chemokine secreted levels ( $\left.{ }^{*} p<0.05\right)$. Circles represent M-MDM(LPS/IFN $\left.\gamma\right)$, squares represent GM-MDM(LPS/IFN $\left.\gamma\right)$ and triangles represent Mob-MDM(LPS/IFN $\gamma)$. 
Canonical pathway enrichment analysis identified several predicted signaling pathways that were significantly altered in Mob-MDM(LPS/ IFN $\gamma$ ) relative to both M-MDM(LPS/ IFN $\gamma$ ) and GM-MDM(LPS/IFN $\gamma)$, but not between the latter two MDM types. These comprised, among others, activated NF- $\mathrm{kB}$ signaling, TREM1 signaling, and repressed p53 signaling (Table 2).

Table 2. Signaling pathways that are uniquely modulated in lipopolysaccharide (LPS)/interferon $\gamma$ (IFN $\gamma$ )-activated human monocyte-derived macrophages (MDMs) that were differentiated with HK M. obuense (Mob-MDM(LPS/IFN $\gamma)$ ) relative to those differentiated with macrophage colony-stimulating factor (M-MDM(LPS/IFN $\gamma)$ ) and granulocyte/macrophage colony-stimulating factor (GM-MDM(LPS/IFN $\gamma)$ ).

\begin{tabular}{|c|c|c|}
\hline \multirow[b]{2}{*}{ Signaling Pathway } & \multicolumn{2}{|c|}{ Activation Z-Score } \\
\hline & $\begin{array}{c}\text { Mob-MDM(LPS/IFN } \gamma) \\
\text { vs. } \\
\text { GM-MDM(LPS/IFN } \gamma) \text { and } \\
\text { M-MDM(LPS/IFN } \gamma)\end{array}$ & $\begin{array}{c}\text { M-MDM(LPS/IFN } \gamma) \\
\text { vs. } \\
\text { GM-MDM(LPS/IFN } \gamma)\end{array}$ \\
\hline Endothelin-1 Signaling & 2.65 & -0.38 \\
\hline NF- $\kappa B$ Signaling & 2.65 & -0.82 \\
\hline Estrogen-mediated S-phase Entry & 2.45 & 1.63 \\
\hline Mitotic Roles of Polo-Like Kinase & 2.45 & 0.82 \\
\hline Role of IL-17F in Allergic Inflammatory Airway Diseases & 2.24 & 0.45 \\
\hline TREM1 Signaling & 2.24 & -0.45 \\
\hline p53 Signaling & -2.65 & 1.13 \\
\hline
\end{tabular}

We then performed topological network analysis to predict the activation or inhibition of potential upstream regulators of the detected set of differentially expressed genes unique to Mob-MDM(LPS/IFN $\gamma$ ). A total of 186 upstream regulators (121 activated (z-score $\geq 2$ ) and 65 inhibited (z-score $\leq-2)$ ) were identified in Mob-MDM(LPS/IFN $\gamma$ ) relative to MMDM(LPS/IFN $\gamma$ ) and GM-MDM(LPS/IFN $\gamma$ ), but not between the latter MDM types (Supplementary Materials Table S3). Those predicted upstream regulators comprised various cytokines/chemokines, chemical drugs, transmembrane receptors, bacterial components, and others. CSF2 (GM-CSF; z-score $=4.61)$ and the LY294002 $(\mathrm{z}$-score $=-4.31)$ were predicted as the top activated and inhibited upstream regulators, respectively (Supplementary Materials Table S3). In addition, gene-set and network analysis identified biological functions $(n=100)$ significantly affected by the uniquely differentially expressed transcripts in Mob$\operatorname{MDM}(\mathrm{LPS} / \mathrm{IFN} \gamma)$ compared to M-MDM(LPS/IFN $\gamma)$ and GM-MDM(LPS/IFN $\gamma)$, but not between the latter two MDM types (Supplementary Materials Table S4). The identified biological functions predicted to be uniquely activated (z-score $\geq 2)$ in Mob-MDM(LPS/IFN $\gamma$ ) included, among others, activation of blood cells/leukocytes, migration/cell movement of myeloid cells and $\mathrm{M} \varphi \mathrm{s}$, and synthesis of reactive oxygen species (Supplementary Materials Table S4). Collectively, RNA-Seq analysis revealed a distinct transcriptome profile of Mob-MDM(LPS/IFN $\gamma)$ from both M-MDM(LPS/IFN $\gamma)$ and GM-MDM(LPS/IFN $\gamma)$.

\section{Discussion}

$\mathrm{M} \varphi$ activation is a multifaceted and dynamic mechanism that can generate various $\mathrm{M} \varphi$ states with a diverse range of functional outcomes [21,22]. However, the preactivation process whereby monocytes are differentiated into $\mathrm{M} \varphi$ s plays a dominant role in shaping the final activation state of $\mathrm{M} \varphi$ s irrespective of the adopted stimulus. Traditionally, GM-CSF and M-CSF have been widely used to induce monocyte-to-M $\varphi$ differentiation and to prime $\mathrm{M} \varphi$ s toward the nonactivated pre-M1 (GM-MDM) and pre-M2 (M-MDM) $\mathrm{M} \varphi$ phenotypes, respectively [23]. Evidence from previous studies has confirmed the immunomodulatory properties and immunotherapeutic potentials of $\mathrm{HK}$ whole-cell mycobacteria namely, M. vaccae and M. obuense. More importantly, the safety of both HK 
mycobacteria is proven and well documented in several studies whereby mild adverse events were noted following the administration of either preparation to cancer $[12,13,24]$ and human immunodeficiency virus (HIV) [25] patients. Thus, HK whole-cell preparations of $M$. vaccae and M. obuense have a major advantage over Bacillus Calmette-Guérin (BCG) in terms of their favorable safety and tolerability. Despite its successful usage in the treatment of nonmuscle/noninvasive bladder cancer, BCG might cause in certain cases severe and life-threatening adverse events such as local or systemic infections with BCG [26]. It has been well documented from earlier studies that various viable and killed mycobacterial species can alter the activation state of human $\mathrm{M} \varphi s[27,28]$. In this manner, data from our previous phenotypic, functional, and transcriptomic studies have indicated that HK $M$. obuense, an immunomodulator of both the innate and adaptive immune responses, promotes the differentiation of human monocytes into a nonactivated $\mathrm{M} \varphi$ type (Mob-MDM) that acquire proinflammatory properties suggestive of an M1-like M $\varphi$ phenotype [18]. In this study, we aimed to gain deeper insights into the cytokine/chemokine secretion patterns and transcriptome profiles of Mob-MDMs, M-MDMs, and GM-MDMs following their LPS/IFN $\gamma$-mediated activation.

In the present work and consistent with previous reports, GM-MDM(LPS/IFN $\gamma$ ) produced significantly higher levels of CCL22 [7,29], IL-6 [29,30], IL-12/23p40 [7,29,31], and IL-23p19/p40 [19] and significantly lower levels of IL-10 [29-32] as compared to M$\operatorname{MDM}(\mathrm{LPS} / \mathrm{IFN} \gamma)$. On the other hand, a study by Vogel et al. did not find any significant difference in IL-10 secretion between M-MDM(LPS/IFN $\gamma$ ) and GM-MDM(LPS/IFN $\gamma$ ) [8]. Moreover, in sharp contrast to Verreck et al., who reported the absence of detectable levels of IL-12/23p40 in M-MDM(LPS/IFN $\gamma$ ) culture supernatants [19], findings from this study and from previous studies $[7,31]$ have found M-MDM(LPS/IFN $\gamma$ ) to release detectable amounts of IL-12/23p40, although, to a significantly lower level than that released by GM-MDM(LPS/IFN $\gamma)$. Additionally, previous studies have reported that IL-12p70 [7,32] and TNF- $\alpha[30,32]$ were secreted at significantly higher levels by GM$\mathrm{MDM}(\mathrm{LPS} / \mathrm{IFN} \gamma)$ relative to $\mathrm{M}-\mathrm{MDM}(\mathrm{LPS} / \mathrm{IFN} \gamma)$. This study only showed an overall trend, but with no statistical significance, toward increased secretion of both cytokines by GM-MDM(LPS/IFN $\gamma)$ relative to M-MDM(LPS/IFN $\gamma)$. Contrary to previous studies [29,32], which found CCL5 to be secreted at significantly higher levels by GM-MDM(LPS/IFN $\gamma$ ) relative to M-MDM(LPS/IFN $\gamma)$, results from the current study demonstrated the opposite. Hence, the above-mentioned variations in the differential secretion of cytokines and chemokines between M-MDM(LPS/IFN $\gamma$ ) and GM-MDM(LPS/IFN $\gamma$ ) could be related to differences in the activation method employed by different studies, more specifically the period of exposure to LPS and IFN $\gamma$ and the concentration of each activating stimulus. The profile and level of cytokines/chemokines secreted by M $\varphi$ s have been widely adopted as signature markers to discriminate between the two activated M1- and M2-M $\varphi$ phenotypes [33]. Classically activated human $\mathrm{M} 1-\mathrm{M} \varphi$ s are typically characterized by their IL-10 ${ }^{\text {low }}$, IL-12/23p40high and/or IL-12p70 high , and IL-23p19/p40 high phenotype [1,34]. In contrast, alternatively activated M2-M $\varphi$ s have an IL-10 high, IL-12/23p40 low and/or IL$12 \mathrm{p} 70^{\text {low }}$, and IL-23p19/p40 low phenotype [35]. Several reports utilizing CSF-differentiated human MDMs as in vitro models to study $\mathrm{M} \varphi$ have indicated that M-CSF and GM-CSF are crucial determinants for shaping the functional profiles of activated M $\varphi s$ [29,36]. In support of this notion, this study has shown that M-MDM(LPS/IFN $\gamma)$ display a cytokine secretion profile (IL-10 high , IL-12/23p40 low , IL-12p70 low , and IL23p19/p40 neg ) characteristic of the M2-M $\varphi$ phenotype, while GM-MDM(LPS/IFN $\gamma$ ) display a cytokine secretion profile (IL-10 low , IL-12/23p40high, IL-12p70 high, and IL23p19/p40high) characteristic of the $\mathrm{M} 1-\mathrm{M} \varphi$ phenotype. These striking differences were also noted at the transcript level whereby RNA-Seq analysis performed in this study revealed higher expression of IL10 and lower expression of IL12B (encodes for IL-12/23p40) and IL23A (encodes for IL-23p19) in M-MDM(LPS/IFN $\gamma$ ) as compared to GM-MDM(LPS/IFN $\gamma$ ). This is in agreement with previous studies where similar patterns of differential mRNA expression between M-MDM(LPS/IFN $\gamma)$ and GM-MDM(LPS/IFN $\gamma)$ were reported for IL10, IL23A [36], and 
IL12B [31]. Therefore, despite being activated with the M1-activating stimuli, LPS and IFN $\gamma, \mathrm{M}-\mathrm{MDM}$ remain trapped in an $\mathrm{M} 2-\mathrm{M} \varphi$ response mode imposed by M-CSF during the stage of monocyte-to-M $\varphi$ differentiation, and such a mode seems to be quite independent of the nature of the subsequent activating stimuli. A key finding in the current study was the demonstration that Mob-MDM(LPS/IFN $\gamma)$ exhibit a distinct cytokine/chemokine secretion profile from that of M-MDM(LPS/IFN $\gamma)$ and GM-MDM(LPS/IFN $\gamma)$. The unique cytokine secretion profile of Mob-MDM(LPS $/ \mathrm{IFN} \gamma)\left(\mathrm{IL}-10^{\text {low }}, \mathrm{IL}-12 / 23 \mathrm{p} 40^{\text {low }}, \mathrm{IL}-12 \mathrm{p} 70^{\text {neg }}\right.$, and IL23p19/p40 low $)$ did not correlate either with that of M1-M $\varphi$ s (IL-12 ${ }^{\text {high }}$ ) or with any of those of the M2-M $\varphi$ subtypes, M2a, M2b, M2c, or M2d, whereby high IL-10 production is a common feature among the four of them [37]. Moreover, the distinctiveness of Mob-MDM(LPS/IFN $\gamma$ ) phenotype was further reinforced by their pattern of low CXCL9 production as compared to both M-MDM(LPS/IFN $\gamma)$ and GM-MDM(LPS/IFN $\gamma)$. A previous study demonstrated that cell wall extracts from HK M. obuense and $M$. vaccae can induce the production of IL-12 and TNF- $\alpha$ by human THP-1-derived macrophages. In this study, IL-12 levels induced by cell wall extract of either of the two HK mycobacteria were comparable to those induced by BCG, while TNF- $\alpha$ levels induced by HK M. vaccae cell wall extract were significantly higher than those induced by BCG [38].

In the current study, RNA-Seq analysis was carried out to compare and contrast the transcriptome profiles of the three LPS/IFN $\gamma$-activated MDM types. RNA-Seq analysis identified 1546 transcripts that were significantly differentially expressed among MMDM(LPS/IFN $\gamma)$, GM-MDM(LPS/IFN $\gamma$ ), and Mob-MDM(LPS/IFN $\gamma$ ). A total of 417 transcripts were found to be selectively modulated in Mob-MDM(LPS/IFN $\gamma$ ), but not altered between M-MDM(LPS/IFN $\gamma$ ) and GM-MDM(LPS/IFN $\gamma$ ) (Supplementary Materials Table S2). Mob-MDM(LPS/IFN $\gamma$ ) selective transcripts encompassed a specific group of upregulated proinflammatory chemokines, namely CXCL1, CXCL2, CXCL3, and CXCL5. These four chemokines are known to share a common chemokine binding receptor, chemokine (C-X-C) motif receptor 2 (CXCR2), and they serve as potent chemoattractants for neutrophils [33,39]. On the other hand, a different family of proinflammatory chemokine transcripts (CXCL9, CXCL10, and CXL11) was found to be uniquely downregulated in Mob-MDM(LPS/IFN $\gamma$ ). This family of IFN-inducible chemokines exhibits effective T lymphocyte chemoattractant activities and is capable of binding to the cognate chemokine receptor, CXCR3 [40,41]. Moreover, other signature proinflammatory cytokines (e.g., IFNG, $I L 1 B$, and IL36G) were significantly upregulated in Mob-MDM(LPS/IFN $\gamma$ ) versus both M-MDM(LPS/IFN $\gamma)$ and GM-MDM(LPS/IFN $\gamma)$. Several studies have highlighted the contribution of IL-36 $\gamma$ (encoded by IL-36G) in polarizing immune cells toward type-1 immune responses, which are pertinent to antitumor immunity [42,43]. It has been previously indicated that human IL-36 $\gamma$ expression is inversely associated with lung and melanoma cancer progression [44]. Transcriptomic data analysis of various immune cell populations purified from human colorectal cancer (CRC) microenvironment has shown that IL36G is expressed at significantly higher levels in $\mathrm{M} 1-\mathrm{M} \varphi$ s compared to all other immune cells, including $\mathrm{M} 2-\mathrm{M} \varphi \mathrm{s}[45,46]$. Further exploration of the tumor microenvironment has uncovered a correlation between the pattern of $\mathrm{M} \varphi$ IL-36 $\gamma$ expression and two positive prognostic markers for CRC which comprise $\mathrm{CD} 4^{+}$central memory T-cell infiltration and augmented density of B cells in tertiary lymphoid structures [46]. IL-36 $\gamma$ has been also reported to confer protection against severe influenza infection through enhancing the survival of mouse lung alveolar M $\varphi$ s and restraining the replication of the virus [47]. Alveolar M $\varphi s$ isolated from uninfected IL-36 $\gamma$ knockout mice exhibited an M2-like $\mathrm{M} \varphi$ phenotype and demonstrated an increased and rapid rate of apoptosis post influenza infection [47]. Taking into account that HK $M$. obuense is currently being assessed in an ongoing clinical trial (NCT04442048) for its capacity to decrease the occurrence and severity of coronavirus disease 2019 (COVID-19)-related symptoms in cancer patients, it is noteworthy to further investigate whether there is a correlation of serum IL-36 $\gamma$ levels with the clinical outcomes in those patients. Results of our study identified a group of solute carriers that were selectively modulated in Mob-MDM(LPS/IFN $\gamma$ ), whereby SLC27A2, SLC7A11, and SLC51B 
displayed an increased expression, while SLC8A1, SLC2A8, SLC2A5, and SLC6A9 showed a decreased expression. Key physiological functions for the solute carrier family include: transport of ions, uptake of nutrients, and elimination of cellular waste [48]. However, a limited number of studies have addressed the functions of the above-modulated solute carriers in human $\mathrm{M} \varphi \mathrm{s}$. For instance, heat-inactivated $M$. tuberculosis lysate was found to induce SLC7A11 expression in U937-derived human M $\varphi$ s [49], while SLC8A1 mediated the release of the proinflammatory cytokine, $\mathrm{TNF} \alpha$, by human lung $\mathrm{M} \varphi \mathrm{s}$ [50]. SIGLEC10 was among the top 10 transcripts of its category (others) that were uniquely and significantly downregulated in Mob-MDM(LPS/IFN $\gamma$ ). The interaction between sialic acid-binding Ig-like lectin 10 (Siglec-10) on the surface of $\mathrm{M} \varphi$ s with CD24, commonly overexpressed on numerous human cancers, has been previously described to be involved in the suppression of $\mathrm{M} \varphi$-mediated immune responses to cancer [51]. Targeting the CD24-Siglec-10 signaling axis stands as a promising approach for cancer immunotherapy whereby blocking Siglec-10 on human MDMs resulted in a significant increase in the phagocytic capacity of tumor cells [52]. In this context, it would be of interest to evaluate the cytotoxic activity of Mob-MDM(LPS/IFN $\gamma)$ in vitro against CD24-expressing human cancer cell lines as well as in vivo in humanized mouse cancer models.

RNA-Seq profiling coupled with pathways network analysis predicted nuclear factor$\mathrm{KB}(\mathrm{NF}-\mathrm{KB})$ and triggering receptor expressed on myeloid cells 1 (TREM1) signaling pathways to be significantly activated in Mob-MDM(LPS/IFN $\gamma$ ) relative to both M-MDM(LPS/ IFN $\gamma$ ) and GM-MDM(LPS/IFN $\gamma)$. The transcription factor, NF- $\mathrm{kB}$, is a master regulator of inflammatory gene expression in $\mathrm{M} \varphi \mathrm{s}$ [53], and it also plays a crucial role in maintaining $\mathrm{M} \varphi$ viability [54]. It would be reasonable to expect that activation of the NF- $\kappa B$ signaling pathway in $\mathrm{M} \varphi$ s would induce the release of proinflammatory mediators (e.g., IL-6, inducible nitric oxide synthase (iNOs), and TNF- $\alpha$ ) [55], hence promoting the M1-M $\varphi$ phenotype as previously indicated [56,57]. Of note, TREM1 has been previously reported to be an inducer of the $\mathrm{M} 1-\mathrm{M} \varphi$ phenotype [58] and to extend the survival of inflammatory $\mathrm{M} \varphi \mathrm{s}$ [59]. TREM1 activation was shown to initiate a cascade of downstream signaling events that would lead to the secretion of various M1 proinflammatory cytokines [58]. Upstream regulator analysis identified colony-stimulating factor 2 (CSF2; also known as GM-CSF) as the top activated upstream regulator in Mob-(LPS/IFN $\gamma$ ) compared with both M-MDM(LPS/IFN $\gamma$ ) and GM-MDM(LPS/IFN $\gamma$ ). GM-CSF has been previously reported to play a pivotal role in controlling $M$. tuberculosis infection in human MDMs in vitro, whereby the degree of infection control was positively correlated with GM-CSF secreted levels and with activated GM-CSF signaling pathways in infected $\mathrm{M} \varphi \mathrm{s}[60,61]$. Further studies are clearly warranted to evaluate the antimycobacterial properties of Mob-MDM(LPS/IFN $\gamma$ ). Taken together, the cytokine/chemokine release pattern of Mob-MDM(LPS/IFN $\gamma$ ), combined with their transcriptome profile, strongly point out to a unique $\mathrm{M} \varphi$ phenotype, which is quite distinct from that of M-MDM(LPS/IFN $\gamma$ ) and GM-MDM(LPS/IFN $\gamma$ ).

Previous work by our group indicated that nonactivated Mob-MDMs possess a potent in vitro antitumor activity whereby they displayed a higher cytostatic effect against the human pancreatic cancer cell line, BxPC3, when compared to nonactivated M-MDMs, but their effect was comparable to that of nonactivated GM-MDMs [18]. In fact, HK M. obuense was shown to exhibit marked immunotherapeutic effects when given in combination with chemotherapy, in patients with metastatic pancreatic cancer [13], or in combination with checkpoint inhibitors in patients with advanced melanoma [14]. In view of the aforementioned findings, it is reasonable to suggest that the antitumor activity of nonactivated or LPS/IFN $\gamma$-activated Mob-MDMs is independent of their ability to release IL-12 and might be attributed to a unique set of Mob-MDM-related genes (e.g., CSF2 and IL36G). Thus, the potential association of these candidate genes with HK M. obuense-mediated antitumor activity needs to be pursued in future studies. More recently, there has been a strong but renewed interest in novel $\mathrm{M} \varphi$-based approaches in cancer immunotherapy whereby the use of chimeric antigen receptors $\mathrm{M} \varphi \mathrm{s}$ (CAR-Ms), currently under development, has proven to be a promising immunotherapeutic tool against cancer [62,63]. In this manner, 
results from this study might pave the way for a potential application of HK M. obuense in novel cell-based immunotherapeutic modalities such as the adoptive cell transfer of autologous Mob-MDM(LPS/IFN $\gamma$ ) to patients with solid tumors.

\section{Materials and Methods}

\subsection{Blood Collection}

Human whole-blood samples (150-200 mL) were obtained from anonymous phenotypically healthy adult donors through the blood bank at Nini Hospital. Whole blood was collected in plastic bags containing citrate-phosphate-dextrose-adenine and stored at room temperature for $1 \mathrm{~h}$ prior to being processed.

\subsection{Monocyte Isolation and Generation of MDMs}

Whole blood was diluted with an equal volume of complete Roswell Park Memorial Institute (RPMI; Merck, Darmstadt, Germany) 1640 medium (containing $100 \mathrm{U} / \mathrm{mL}$ penicillin, $100 \mu \mathrm{g} / \mathrm{mL}$ streptomycin penicillin, and $2 \mathrm{mM}$ L-glutamine; Merck, Darmstadt, Germany). Diluted blood was layered over Ficoll-Paque Plus (GE Healthcare, Buckingham, UK) and centrifuged at $400 \times g$ for $40 \mathrm{~min}$ at $20^{\circ} \mathrm{C}$. Peripheral blood mononuclear cells (PBMCs) were removed from the interface and washed twice with Dulbecco's phosphate-buffered saline (DPBS; Merck, Darmstadt, Germany) by centrifugation at $200 \times \mathrm{g}$ for $15 \mathrm{~min}$ at $20^{\circ} \mathrm{C}$ to get rid of platelets. PBMCs were assessed for viability using the trypan blue exclusion method and were always $>95 \%$ viable. Later, PBMCs were seeded into $75 \mathrm{~cm}^{2}$ tissue culture flasks at a density of $1.5 \times 10^{6}$ cells $/ \mathrm{mL}$ of complete RPMI medium and incubated overnight at $37^{\circ} \mathrm{C}$ in a $5 \% \mathrm{CO}_{2}$ humidified incubator. Cells were then washed thoroughly with DBPS, and adherent monocytes were permitted to differentiate for 5 days into $\mathrm{M} \varphi \mathrm{s}$ in complete RPMI 1640 medium supplemented with 7.5\% heat-inactivated pooled human $A B$ serum (ZenBio, Durham, NC, USA) and with optimal concentrations [7,18,32] of M-CSF (100 ng/mL), GM-CSF (100 ng/mL) (R\&D Systems, Abingdon, UK), or $30 \mu \mathrm{g} / \mathrm{mL}$ HK $M$. obuense (NCTC13365, Immodulon Therapeutics, UK) to generate M-MDMs, GM-MDMs, and Mob-MDMs, respectively. MDM purity, as assessed by flow cytometry, was $\sim 80-85 \%$ after 5 days of differentiation.

\subsection{Activation of $M D M s$}

Following the 5-day monocyte-to-M $\varphi$ differentiation period, M-MDMs, GM-MDMs, and Mob-MDMs were washed thoroughly with cold DPBS and detached by gentle scraping in cold complete RPMI 1640 medium. The viability of MDMs was $~ 75-80 \%$, as evaluated by the trypan blue dye exclusion method. Detached MDMs were seeded in a 24-well culture plate at a density of $3 \times 10^{5}$ cells/well, cultured in complete RPMI 1640 medium supplemented with $10 \%$ heat-inactivated pooled human $\mathrm{AB}$ serum, and were activated with LPS from Escherichia coli O111:B4 (100 ng/mL; Merck, Darmstadt, Germany) and IFN $\gamma$ (20 ng $/ \mathrm{mL}$; R\&D Systems, Abingdon, UK) for $24 \mathrm{~h}$ at $37^{\circ} \mathrm{C}$ in a $5 \% \mathrm{CO}_{2}$-humidified incubator [31,32]. LPS/IFN $\gamma$-activated M-MDMs, GM-MDMs, and Mob-MDMs were referred to as M-MDM(LPS/IFN $\gamma)$, GM-MDM(LPS/IFN $\gamma)$, and Mob-MDM(LPS/IFN $\gamma)$, respectively.

\subsection{Measurement of Cytokine and Chemokine Levels in MDM Culture Supernatants}

Supernatants of different LPS/IFN $\gamma$-activated MDM cultures were collected by centrifugation at $1000 \times \mathrm{g}$ for $15 \mathrm{~min}$ at $4{ }^{\circ} \mathrm{C}$, aliquoted, and stored at $-80{ }^{\circ} \mathrm{C}$ for later cytokine/chemokine analysis. Levels of different cytokines (IL-6, IL-10, IL-12/23p40, IL12p70, IL-23p19/p40, M-CSF, TGF- $\beta 1$, and TNF- $\alpha$ ) and chemokines (CCL2, CCL5, CCL22, CXCL8, and CXCL9) were measured in MDM culture supernatants using sandwich enzymelinked immunosorbent assay (ELISA) following the protocol provided by the manufacturer (R\&D Systems, Abingdon, UK). Samples were tested in duplicate, and optical densities of samples were recorded using a Multiskan Ascent microplate reader (Thermo Fisher Scientific, Waltham, MA, USA). 


\subsection{RNA Extraction from $M D M$}

Total RNA was extracted from LPS/IFN $\gamma$-activated MDMs with the RNeasy Plus kit (Qiagen, Courtaboeuf, France) following the manufacturer's recommendations. The RNA yield of samples was quantified using the NanoDrop 2000 spectrophotometer (Thermo Fisher Scientific, Waltham, MA, USA). RNA Quality was evaluated by calculating RNA integrity numbers (RINs) through the use of the Agilent 2100 Bioanalyzer (Agilent Technologies, Santa Clara, CA, USA) according to the manufacturer's guidelines. RNA samples had a mean RIN of 8.9 (range $=8.7-9.2$ ).

\subsection{Library Preparation and RNA-Seq}

A total of $800 \mathrm{ng}$ of RNA was subjected to ribosomal RNA depletion using the Low Input RiboMinus Eukaryote System v2 (Thermo Fisher Scientific, Waltham, MA, USA) following the manufacturer's protocol. Samples were then concentrated by vacuum centrifugation, followed by the construction of whole-transcriptome libraries using the Ion Total RNA-Seq Kit v2 (Thermo Fisher Scientific, Waltham, MA, USA) according to the manufacturer's instructions. Assessment of the size distribution of samples was carried out by using the Agilent 2100 Bioanalyzer coupled with the 6000 RNA Pico kit. Library concentrations were determined using the Agilent DNA 1000 assay on the 2100 Bioanalyzer according to the manufacturer's procedure. Barcoded whole-transcriptome libraries were then diluted to $66 \mathrm{pM}$ and pooled equally (13 $\mu \mathrm{L}$ each for a total of $26 \mu \mathrm{L}$ ) for sequencing with two samples per template preparation. All template reactions were carried out on the Ion Chef Instrument with the Ion PI Hi-Q Chef 200 kit (Thermo Fisher Scientific, Waltham, MA, USA) based on the manufacturer's protocol. Finally, barcoded samples were loaded onto Ion PI Chips v3 (Thermo Fisher Scientific, Waltham, MA, USA), and sequencing was performed with an Ion Proton sequencer (Thermo Fisher Scientific, Waltham, MA, USA) according to the manufacturer's instructions.

\subsection{RNA-Seq Data Analysis}

An average of 36 million reads/sample were sequenced and attained $90 \%$ uniformity of coverage. Alignment of reads was performed using Partek flow and a two-step alignment process. Unaligned reads were initially aligned to hg19 (human reference genome) using the STAR algorithm [64]. After the initial alignment, all unaligned reads were then realigned with Bowtie2 version 2.1.0 [65], whereby reads from both alignment steps were then pooled. Transcripts were then quantified using a modified version of the expectationmaximization (E/M) algorithm, as previously defined [66]. A pseudocount was added to all values with reads per kilobase per million $(\mathrm{RPKM})<1.0$ followed by $\log$ (base 2 ) transformation and quantile normalization. The fixed-effects model with ANOVA was employed to identify transcripts significantly differentially expressed $(p<0.05$ and 2-fold change thresholds) among M-MDM(LPS/IFN $\gamma$ ), GM-MDM(LPS/IFN $\gamma$ ), and Mob$\operatorname{MDM}(\mathrm{LPS} / \mathrm{IFN} \gamma)(n=1546$ transcripts, Supplementary Materials Table S1). Analysis was carried out in the R language environment [67]. Select transcripts were also evaluated in pairwise comparisons (e.g., M-MDM(LPS/IFN $\gamma$ ) compared to GM-MDM(LPS/IFN $\gamma$ )) using $t$-tests with random variance models. Hierarchical clustering analysis was applied to distinguish, among the differentially expressed genes, those with different patterns of expression among the three LPS/IFN $\gamma$-activated MDM types [68,69]. Functional pathways analysis, including gene-set enrichment and gene-gene network analysis, of differentially expressed transcripts was conducted using Ingenuity Pathways Analysis as previously described [70]. Raw data for M-MDM(LPS/IFN $\gamma)$, GM-MDM(LPS/IFN $\gamma)$, and Mob$\operatorname{MDM}(\mathrm{LPS} / \mathrm{IFN} \gamma$ ) will be deposited into the Gene Expression Omnibus (GEO) under the dataset series GSE102492.

\subsection{Statistical Analysis}

Statistical analysis was carried out using GraphPad Prism software (version 6; GraphPad Inc., San Diego, CA, USAe). Cytokine/chemokine data are presented as mean 
values \pm standard error of the mean (SEM). One-way ANOVA, followed by Tukey's multiple comparison post-hoc test, was used to analyze cytokine/chemokine data. Values of $p<0.05$ denoted the existence of a statistically significant difference between compared groups.

Supplementary Materials: The following are available online at https:/ /www.mdpi.com/article/10 $.3390 / \mathrm{ijms} 22137214 / \mathrm{s} 1$.

Author Contributions: Conceptualization, S.B., H.K. and G.M.B.; investigation, S.B., E.E.-D. and T.M.; formal analysis, H.M., S.M., M.A. and C.A., resources, S.M., M.A., C.A. and H.K.; writingoriginal draft preparation, S.B.; writing-review and editing H.K. and G.M.B.; supervision, G.M.B.; project administration, G.M.B., funding, G.M.B. All authors have read and agreed to the published version of the manuscript.

Funding: This research was funded by a grant from Immodulon Therapeutics Ltd., UK to G.M.B.

Institutional Review Board Statement: The study was conducted according to the guidelines of the Declaration of Helsinki and approved by the institutional review board (IRB) at the Faculty of Medicine and Medical Sciences, University of Balamand (IRB Registration No.: IRB/O/009-r 8/316), as well as by the Ethics Committee at Nini Hospital (IRB registration No.: IRB-F-01).

Informed Consent Statement: Each blood donor who participated in the study provided written informed consent.

Data Availability Statement: Raw data for M-MDM(LPS/IFN $\gamma$ ), GM-MDM(LPS/IFN $\gamma)$, and MobMDM(LPS/IFN $\gamma$ ) will be deposited into the Gene Expression Omnibus (GEO) under the dataset series.

Conflicts of Interest: S.M. and C.A. are shareholders at Immodulon Therapeutics Ltd., UK. The remaining authors declare no potential conflict of interest with respect to the research, authorship, and/or publication of this article.

\section{References}

1. Murray, P.J.; Allen, J.E.; Biswas, S.K.; Fisher, E.A.; Gilroy, D.W.; Goerdt, S.; Gordon, S.; Hamilton, J.A.; Ivashkiv, L.B.; Lawrence, T.; et al. Macrophage activation and polarization: Nomenclature and experimental guidelines. Immunity 2014, 41, 14-20. [CrossRef]

2. Italiani, P.; Boraschi, D. From monocytes to M1/M2 macrophages: Phenotypical vs. functional differentiation. Front. Immunol. 2014, 5, 514. [CrossRef] [PubMed]

3. Orecch, M.; Ghosheh, Y.; Pramod, A.B.; Ley, K. Corrigendum: Macrophage polarization: Different gene signatures in M1(LPS+) Vs. classically and M2(LPS-) vs. alternatively activated macrophages. Front. Immunol. 2020, 11, 234. [CrossRef]

4. Lacey, D.C.; Achuthan, A.; Fleetwood, A.J.; Dinh, H.; Roiniotis, J.; Scholz, G.M.; Chang, M.W.; Beckman, S.K.; Cook, A.D.; Hamilton, J.A. Defining GM-CSF- and macrophage-CSF-dependent macrophage responses by in vitro models. J. Immunol. 2012, 188, 5752-5765. [CrossRef] [PubMed]

5. Buchacher, T.; Ohradanova-Repic, A.; Stockinger, H.; Fischer, M.B.; Weber, V. M2 polarization of human macrophages favors survival of the intracellular pathogen chlamydia pneumoniae. PLoS ONE 2015, 10, e0143593. [CrossRef] [PubMed]

6. Trus, E.; Basta, S.; Gee, K. Who's in charge here? Macrophage colony stimulating factor and granulocyte macrophage colony stimulating factor: Competing factors in macrophage polarization. Cytokine 2020, 127, 154939. [CrossRef]

7. Rey-Giraud, F.; Hafner, M.; Ries, C.H. In vitro generation of monocyte-derived macrophages under serum-free conditions improves their tumor promoting functions. PLoS ONE 2012, 7, e42656. [CrossRef] [PubMed]

8. Vogel, D.Y.; Glim, J.E.; Stavenuiter, A.W.; Breur, M.; Heijnen, P.; Amor, S.; Dijkstra, C.D.; Beelen, R.H. Human macrophage polarization in vitro: Maturation and activation methods compared. Immunobiology 2014, 219, 695-703. [CrossRef]

9. Rook, G.A.; Adams, V.; Hunt, J.; Palmer, R.; Martinelli, R.; Brunet, L.R. Mycobacteria and other environmental organisms as immunomodulators for immunoregulatory disorders. Springer Semin. Immunopathol. 2004, 25, 237-255. [CrossRef]

10. Kleinnijenhuis, J.; Oosting, M.; Joosten, L.A.; Netea, M.G.; Van Crevel, R. Innate immune recognition of mycobacterium tuberculosis. Clin. Dev. Immunol. 2011, 2011, 405310. [CrossRef]

11. Killick, K.E.; Ni Cheallaigh, C.; O'Farrelly, C.; Hokamp, K.; MacHugh, D.E.; Harris, J. Receptor-mediated recognition of mycobacterial pathogens. Cell. Microbiol. 2013, 15, 1484-1495. [CrossRef] [PubMed]

12. Stebbing, J.; Dalgleish, A.; Gifford-Moore, A.; Martin, A.; Gleeson, C.; Wilson, G.; Brunet, L.R.; Grange, J.; Mudan, S. An intra-patient placebo-controlled phase I trial to evaluate the safety and tolerability of intradermal IMM-101 in melanoma. Ann. Oncol. 2012, 23, 1314-1319. [CrossRef] [PubMed]

13. Dalgleish, A.G.; Stebbing, J.; Adamson, D.J.; Arif, S.S.; Bidoli, P.; Chang, D.; Cheeseman, S.; Diaz-Beveridge, R.; Fernandez-Martos, C.; Glynne-Jones, R.; et al. Randomised, open-label, phase II study of gemcitabine with and without IMM-101 for advanced pancreatic cancer. Br. J. Cancer 2016, 115, 789-796. [CrossRef] 
14. Dalgleish, A.G.; Mudan, S.; Fusi, A. Enhanced effect of checkpoint inhibitors when given after or together with IMM-101: Significant responses in four advanced melanoma patients with no additional major toxicity. J. Transl. Med. 2018, 16, 227-228. [CrossRef] [PubMed]

15. Fowler, D.; Copier, J.; Wilson, N.; Dalgleish, A.G.; Bodman-Smith, M.D. Mycobacteria activate gammadelta T-cell anti-tumour responses via cytokines from type 1 myeloid dendritic cells: A mechanism of action for cancer immunotherapy. Cancer Immunol. Immunother. 2012, 61, 535-547. [CrossRef]

16. Bazzi, S.; Modjtahedi, H.; Mudan, S.; Akle, C.; Bahr, G.M. Analysis of the immunomodulatory properties of two heat-killed mycobacterial preparations in a human whole blood model. Immunobiology 2015, 220, 1293-1304. [CrossRef] [PubMed]

17. Bazzi, S.; Modjtahedi, H.; Mudan, S.; Achkar, M.; Akle, C.; Bahr, G.M. Immunomodulatory effects of heat-killed mycobacterium obuense on human blood dendritic cells. Innate Immun. 2017, 1753425917727838. [CrossRef]

18. Bazzi, S.; El-Darzi, E.; McDowell, T.; Modjtahedi, H.; Mudan, S.; Achkar, M.; Akle, C.; Kadara, H.; Bahr, G.M. Defining genomewide expression and phenotypic contextual cues in macrophages generated by granulocyte/macrophage colony-stimulating factor, macrophage colony-stimulating factor, and heat-killed mycobacteria. Front. Immunol. 2017, 8, 1253. [CrossRef]

19. Verreck, F.A.; de Boer, T.; Langenberg, D.M.; Hoeve, M.A.; Kramer, M.; Vaisberg, E.; Kastelein, R.; Kolk, A.; de Waal-Malefyt, R.; Ottenhoff, T.H. Human IL-23-producing type 1 macrophages promote but IL-10-producing type 2 macrophages subvert immunity to (myco)bacteria. Proc. Natl. Acad. Sci. USA 2004, 101, 4560-4565. [CrossRef]

20. Pahl, J.H.; Kwappenberg, K.M.; Varypataki, E.M.; Santos, S.J.; Kuijjer, M.L.; Mohamed, S.; Wijnen, J.T.; van Tol, M.J.; Cleton-Jansen, A.M.; Egeler, R.M.; et al. Macrophages inhibit human osteosarcoma cell growth after activation with the bacterial cell wall derivative liposomal muramyl tripeptide in combination with interferon-gamma. J. Exp. Clin. Cancer Res. 2014, 33, 27. [CrossRef] [PubMed]

21. Mosser, D.M.; Edwards, J.P. Exploring the full spectrum of macrophage activation. Nat. Rev. Immunol. 2008, 8, 958-969. [CrossRef]

22. Xue, J.; Schmidt, S.V.; Sander, J.; Draffehn, A.; Krebs, W.; Quester, I.; De Nardo, D.; Gohel, T.D.; Emde, M.; Schmidleithner, L.; et al. Transcriptome-based network analysis reveals a spectrum model of human macrophage activation. Immunity 2014, 40, 274-288. [CrossRef]

23. Hamilton, T.A.; Zhao, C.; Pavicic, P.G., Jr.; Datta, S. Myeloid colony-stimulating factors as regulators of macrophage polarization. Front. Immunol. 2014, 5, 554. [CrossRef]

24. Cananzi, F.C.; Mudan, S.; Dunne, M.; Belonwu, N.; Dalgleish, A.G. Long-term survival and outcome of patients originally given mycobacterium vaccae for metastatic malignant melanoma. Hum. Vaccin Immunother. 2013, 9, 2427-2433. [CrossRef]

25. von Reyn, C.F.; Mtei, L.; Arbeit, R.D.; Waddell, R.; Cole, B.; Mackenzie, T.; Matee, M.; Bakari, M.; Tvaroha, S.; Adams, L.V.; et al. Prevention of tuberculosis in Bacille Calmette-Guerin-primed, HIV-infected adults boosted with an inactivated whole-cell mycobacterial vaccine. AIDS 2010, 24, 675-685. [CrossRef] [PubMed]

26. Decaestecker, K.; Oosterlinck, W. Managing the adverse events of intravesical bacillus Calmette-Guerin therapy. Res. Rep. Urol. 2015, 7, 157-163.

27. Ehrt, S.; Schnappinger, D.; Bekiranov, S.; Drenkow, J.; Shi, S.; Gingeras, T.R.; Gaasterland, T.; Schoolnik, G.; Nathan, C. Reprogramming of the macrophage transcriptome in response to interferon-gamma and Mycobacterium tuberculosis: Signaling roles of nitric oxide synthase-2 and phagocyte oxidase. J. Exp. Med. 2001, 194, 1123-1140. [CrossRef] [PubMed]

28. Thiriot, J.D.; Martinez-Martinez, Y.B.; Endsley, J.J.; Torres, A.G. Hacking the host: Exploitation of macrophage polarization by intracellular bacterial pathogens. Pathog. Dis. 2020, 78. [CrossRef] [PubMed]

29. Verreck, F.A.; de Boer, T.; Langenberg, D.M.; van der Zanden, L.; Ottenhoff, T.H. Phenotypic and functional profiling of human proinflammatory type-1 and anti-inflammatory type-2 macrophages in response to microbial antigens and IFN-gamma- and CD40L-mediated costimulation. J. Leukoc. Biol. 2006, 79, 285-293. [CrossRef]

30. Quero, L.; Hanser, E.; Manigold, T.; Tiaden, A.N.; Kyburz, D. TLR2 stimulation impairs anti-inflammatory activity of M2-like macrophages, generating a chimeric M1/M2 phenotype. Arthritis Res. Ther. 2017, 19, 1-13. [CrossRef]

31. Jaguin, M.; Houlbert, N.; Fardel, O.; Lecureur, V. Polarization profiles of human M-CSF-generated macrophages and comparison of M1-markers in classically activated macrophages from GM-CSF and M-CSF origin. Cell. Immunol. 2013, 281, 51-61. [CrossRef]

32. Bayer, C.; Varani, S.; Wang, L.; Walther, P.; Zhou, S.; Straschewski, S.; Bachem, M.; Soderberg-Naucler, C.; Mertens, T.; Frascaroli, G. Human cytomegalovirus infection of M1 and M2 macrophages triggers inflammation and autologous T-cell proliferation. J. Virol. 2013, 87, 67-79. [CrossRef]

33. Mantovani, A.; Sica, A.; Sozzani, S.; Allavena, P.; Vecchi, A.; Locati, M. The chemokine system in diverse forms of macrophage activation and polarization. Trends Immunol. 2004, 25, 677-686. [CrossRef]

34. Mantovani, A.; Sica, A.; Locati, M. Macrophage polarization comes of age. Immunity 2005, 23, 344-346. [CrossRef]

35. Roszer, T. Understanding the mysterious M2 macrophage through activation markers and effector mechanisms. Mediat. Inflamm. 2015, 2015, 816460. [CrossRef]

36. Mia, S.; Warnecke, A.; Zhang, X.M.; Malmstrom, V.; Harris, R.A. An optimized protocol for human M2 macrophages using M-CSF and IL-4/IL-10/TGF-beta yields a dominant immunosuppressive phenotype. Scand. J. Immunol. 2014, 79, 305-314. [CrossRef] [PubMed]

37. Martinez, F.O.; Gordon, S. The M1 and M2 paradigm of macrophage activation: Time for reassessment. F1000Prime Rep. 2014, 6, 13. [CrossRef] [PubMed] 
38. Yuksel, Z.S.; Buber, E.; Kocagoz, T.; Alp, A.; Saribas, Z.; Acan, N.L. Mycobacterial strains that stimulate the immune system most efficiently as candidates for the treatment of bladder cancer. J. Mol. Microbiol. Biotechnol. 2011, 20, 24-28. [CrossRef] [PubMed]

39. Raman, D.; Sobolik-Delmaire, T.; Richmond, A. Chemokines in health and disease. Exp. Cell Res. 2011, 317, 575-589. [CrossRef]

40. Groom, J.R.; Luster, A.D. CXCR3 ligands: Redundant, collaborative and antagonistic functions. Immunol. Cell Biol. 2011, 89, 207-215. [CrossRef]

41. Metzemaekers, M.; Vanheule, V.; Janssens, R.; Struyf, S.; Proost, P. Overview of the mechanisms that may contribute to the non-redundant activities of interferon-inducible CXC chemokine receptor 3 ligands. Front. Immunol. 2018, 8, 1970. [CrossRef]

42. Bachmann, M.; Scheiermann, P.; Hardle, L.; Pfeilschifter, J.; Muhl, H. IL-36gamma/IL-1F9, an innate T-bet target in myeloid cells. J. Biol. Chem. 2012, 287, 41684-41696. [CrossRef] [PubMed]

43. Vigne, S.; Palmer, G.; Martin, P.; Lamacchia, C.; Strebel, D.; Rodriguez, E.; Olleros, M.L.; Vesin, D.; Garcia, I.; Ronchi, F.; et al. IL-36 signaling amplifies Th1 responses by enhancing proliferation and Th1 polarization of naive CD4+ T cells. Blood 2012, 120, 3478-3487. [CrossRef] [PubMed]

44. Wang, X.; Zhao, X.; Feng, C.; Weinstein, A.; Xia, R.; Wen, W.; Lv, Q.; Zuo, S.; Tang, P.; Yang, X.; et al. IL-36gamma transforms the tumor microenvironment and promotes type 1 lymphocyte-mediated antitumor immune responses. Cancer Cell. 2015, 28, 296-306. [CrossRef] [PubMed]

45. Marisa, L.; de Reynies, A.; Duval, A.; Selves, J.; Gaub, M.P.; Vescovo, L.; Etienne-Grimaldi, M.C.; Schiappa, R.; Guenot, D.; Ayadi, M.; et al. Gene expression classification of colon cancer into molecular subtypes: Characterization, validation, and prognostic value. PLoS Med. 2013, 10, e1001453. [CrossRef]

46. Weinstein, A.M.; Giraldo, N.A.; Petitprez, F.; Julie, C.; Lacroix, L.; Peschaud, F.; Emile, J.F.; Marisa, L.; Fridman, W.H.; Storkus, W.J.; et al. Association of IL-36gamma with tertiary lymphoid structures and inflammatory immune infiltrates in human colorectal cancer. Cancer Immunol. Immunother. 2019, 68, 109-120. [CrossRef] [PubMed]

47. Wein, A.N.; Dunbar, P.R.; McMaster, S.R.; Li, Z.T.; Denning, T.L.; Kohlmeier, J.E. IL-36gamma protects against severe influenza infection by promoting lung alveolar macrophage survival and limiting viral replication. J. Immunol. 2018, 201, 573-582. [CrossRef]

48. Cesar-Razquin, A.; Snijder, B.; Frappier-Brinton, T.; Isserlin, R.; Gyimesi, G.; Bai, X.; Reithmeier, R.A.; Hepworth, D.; Hediger, M.A.; Edwards, A.M.; et al. A call for systematic research on solute carriers. Cell 2015, 162, 478-487. [CrossRef]

49. Cai, Y.; Yang, Q.; Liao, M.; Wang, H.; Zhang, C.; Nambi, S.; Wang, W.; Zhang, M.; Wu, J.; Deng, G.; et al. xCT increases tuberculosis susceptibility by regulating antimicrobial function and inflammation. Oncotarget 2016, 7, 31001-31013. [CrossRef]

50. Staiano, R.I.; Granata, F.; Secondo, A.; Petraroli, A.; Loffredo, S.; Annunziato, L.; Triggiani, M.; Marone, G. Human macrophages and monocytes express functional $\mathrm{Na}(+) / \mathrm{Ca}(2+)$ exchangers 1 and 3. Adv. Exp. Med. Biol. 2013, 961, 317-326.

51. Yin, S.S.; Gao, F.H. Molecular mechanism of tumor cell immune escape mediated by CD24/Siglec-10. Front. Immunol. 2020, 11, 1324. [CrossRef]

52. Barkal, A.A.; Brewer, R.E.; Markovic, M.; Kowarsky, M.; Barkal, S.A.; Zaro, B.W.; Krishnan, V.; Hatakeyama, J.; Dorigo, O.; Barkal, L.J.; et al. CD24 signalling through macrophage Siglec-10 is a target for cancer immunotherapy. Nature 2019, 572, 392-396. [CrossRef]

53. Wang, N.; Liang, H.; Zen, K. Molecular mechanisms that influence the macrophage M1-M2 polarization balance. Front. Immunol. 2014, 5, 614. [CrossRef]

54. Pagliari, L.J.; Perlman, H.; Liu, H.; Pope, R.M. Macrophages require constitutive NF-kappaB activation to maintain A1 expression and mitochondrial homeostasis. Mol. Cell. Biol. 2000, 20, 8855-8865. [CrossRef]

55. Tak, P.P.; Firestein, G.S. NF-kappaB: A key role in inflammatory diseases. J. Clin. Investig. 2001, 107, 7-11. [CrossRef]

56. Connelly, L.; Barham, W.; Onishko, H.M.; Chen, L.; Sherrill, T.P.; Zabuawala, T.; Ostrowski, M.C.; Blackwell, T.S.; Yull, F.E. NF-kappaB activation within macrophages leads to an anti-tumor phenotype in a mammary tumor lung metastasis model. Breast Cancer Res. 2011, 13, R83. [CrossRef]

57. Liu, X.; Li, J.; Peng, X.; Lv, B.; Wang, P.; Zhao, X.; Yu, B. Geraniin inhibits LPS-induced THP-1 macrophages switching to M1 phenotype via SOCS1/NF-kappaB pathway. Inflammation 2016, 39, 1421-1433. [CrossRef] [PubMed]

58. Lo, T.H.; Tseng, K.Y.; Tsao, W.S.; Yang, C.Y.; Hsieh, S.L.; Chiu, A.W.; Takai, T.; Mak, T.W.; Tarng, D.C.; Chen, N.J. TREM-1 regulates macrophage polarization in ureteral obstruction. Kidney Int. 2014, 86, 1174-1186. [CrossRef] [PubMed]

59. Yuan, Z.; Syed, M.A.; Panchal, D.; Joo, M.; Colonna, M.; Brantly, M.; Sadikot, R.T. Triggering receptor expressed on myeloid cells 1 (TREM-1)-mediated Bcl-2 induction prolongs macrophage survival. J. Biol. Chem. 2014, 289, 15118-15129. [CrossRef] [PubMed]

60. Bryson, B.D.; Rosebrock, T.R.; Tafesse, F.G.; Itoh, C.Y.; Nibasumba, A.; Babunovic, G.H.; Corleis, B.; Martin, C.; Keegan, C.; Andrade, P.; et al. Heterogeneous GM-CSF signaling in macrophages is associated with control of Mycobacterium tuberculosis. Nat. Commun. 2019, 10, 1-11. [CrossRef] [PubMed]

61. Mishra, A.; Singh, V.K.; Actor, J.K.; Hunter, R.L.; Jagannath, C.; Subbian, S.; Khan, A. GM-CSF dependent differential control of Mycobacterium tuberculosis infection in human and mouse macrophages: Is macrophage source of GM-CSF critical to tuberculosis immunity? Front. Immunol. 2020, 11, 1599. [CrossRef]

62. Anderson, N.R.; Minutolo, N.G.; Gill, S.; Klichinsky, M. Macrophage-based approaches for cancer immunotherapy. Cancer Res. 2020, 81, 1201-1208. [CrossRef] [PubMed] 
63. Klichinsky, M.; Ruella, M.; Shestova, O.; Lu, X.M.; Best, A.; Zeeman, M.; Schmierer, M.; Gabrusiewicz, K.; Anderson, N.R.; Petty, N.E.; et al. Human chimeric antigen receptor macrophages for cancer immunotherapy. Nat. Biotechnol. 2020, 38, 947-953. [CrossRef] [PubMed]

64. Dobin, A.; Davis, C.A.; Schlesinger, F.; Drenkow, J.; Zaleski, C.; Jha, S.; Batut, P.; Chaisson, M.; Gingeras, T.R. STAR: Ultrafast universal RNA-seq aligner. Bioinformatics 2013, 29, 15-21. [CrossRef] [PubMed]

65. Langmead, B.; Salzberg, S.L. Fast gapped-read alignment with Bowtie 2. Nat. Methods 2012, 9, 357-359. [CrossRef]

66. Xing, Y.; Yu, T.; Wu, Y.N.; Roy, M.; Kim, J.; Lee, C. An expectation-maximization algorithm for probabilistic reconstructions of full-length isoforms from splice graphs. Nucleic Acids Res. 2006, 34, 3150-3160. [CrossRef] [PubMed]

67. Simon, R.; Lam, A.; Li, M.C.; Ngan, M.; Menenzes, S.; Zhao, Y. Analysis of gene expression data using BRB-ArrayTools. Cancer. Inform. 2007, 3, 11-17. [CrossRef] [PubMed]

68. Perou, C.M.; Sorlie, T.; Eisen, M.B.; van de Rijn, M.; Jeffrey, S.S.; Rees, C.A.; Pollack, J.R.; Ross, D.T.; Johnsen, H.; Akslen, L.A.; et al. Molecular portraits of human breast tumours. Nature 2000, 406, 747-752. [CrossRef]

69. Kadara, H.; Shen, L.; Fujimoto, J.; Saintigny, P.; Chow, C.W.; Lang, W.; Chu, Z.; Garcia, M.; Kabbout, M.; Fan, Y.H.; et al. Characterizing the molecular spatial and temporal field of injury in early-stage smoker non-small cell lung cancer patients after definitive surgery by expression profiling. Cancer. Prev. Res. 2013, 6, 8-17. [CrossRef]

70. Kadara, H.; Fujimoto, J.; Yoo, S.Y.; Maki, Y.; Gower, A.C.; Kabbout, M.; Garcia, M.M.; Chow, C.W.; Chu, Z.; Mendoza, G.; et al. Transcriptomic architecture of the adjacent airway field cancerization in non-small cell lung cancer. J. Natl. Cancer Inst. 2014, 106, dju004. [CrossRef] 